\title{
Tudo SE ILUMINA COMO ROMANCE DE MISE-en-abYME: VIAGENS E ESCRITAS COMO FORMAS DE ACESSO AOS ARQUIVOS JUDAICOS E FAMILIARES
}

\author{
EVERYTHING IS ILLUMINATED AS A MISE-EN-ABYME NOVEL: \\ WRITTEN JOURNEYS AS WAYS OF ACCESS TO JEWISH AND FAMILY ARCHIVES \\ Humberto Fois-Braga
}

Universidade Federal de Juiz de Fora Juiz de Fora, Brasil

\begin{abstract}
Resumo
O artigo discute como na obra Tudo se Ilumina a experiência de viagem do personagem, que parte em busca das memórias judaicas de seu avô, se configura em matéria-prima para o romance que o mesmo vem escrevendo com o intuito construir para si um lugar na árvore genealógica de sua família. Assim, analisa-se como que o encontro do viajante-escritor com a personagem Lista se torna o clímax da viagem e a inspiração que desencadeia a escrita do romance. Percebe-se uma circularidade no anarquivamento das memórias do Holocausto empreendido por este judeu norte-americano: o entendimento de seu lugar na história começa na viagem à terra de seu avó expulso pelos nazistas, mas na impossibilidade de um reencontro com o passado, posto que o vilarejo buscado já não existe, este processo continua na escrita ficcional que recupera tais acontecimentos a partir dos traços e resíduos deixados pelas experiências do vivido.
\end{abstract}

Palavras-chave: viagem; alegoria; arquivos; judaísmo; escrita.

\begin{abstract}
The article discusses how in the book Everything is Illuminated the travel experience of the character, who sets off in search of Jewish memories of his grandfather, consists of raw-material for the novel he is writing in order to secure a place in his family tree. Thus, we analyze how the meeting of Jonathan and Lista becomes the climax of the travel and the inspiration to write his novel. It can be argued that there is a circularity to the unarchiving of the memories of the Holocaust undertaken by the main character: The understanding that his
\end{abstract}

\section{Résumé}

L'article explique comment dans l'œuvre Tout est illuminé l'expérience de voyage du personnage, qui va à la recherche des mémoires de son grand-père juif, devient la matière première pour le roman qu'il est en train d'écrire ayant pour but la construction d'une place pour lui dans la généalogie de sa famille. Ainsi, on analyse comment la rencontre du voyageur-écrivain avec la personnage Lista devient le point culminant du voyage et l'inspiration qui déclenche l'écriture du roman. On remarque une circularité dans anarchivement des mémoires de l'Holocauste 
place in the story begins with the trip to his grandfather's homeland, but in the impossibility of a reconnection with the past, since the village sought does not exist anymore, this process continues in the fictional writing that recovers such happenings from the traces and residues left by what was experienced.

Keywords: traveling; allegory; archives; judaism; writing. entrepris par ce juif-américain: la compréhension de sa place dans l'histoire commence par le voyage vers la terre de son grand-père chassé par les nazis, mais dans l'impossibilité d'une rencontre avec le passé, puisque le village recherchée n'existe plus, ce processus se poursuit dans l'écriture fictionnelle qui rattrape ces événements à partir des traces et des résidus laissés par les expériences vécues. Mots-clés: voyage. allégorie. archives. judaïsme. écriture.

A questáo do Holocausto, e dos dramas vivenciados pelos judeus e seus familiares, é algo que se torna recorrente na literatura. Porém, com o passar do tempo, e com a natural morte daqueles judeus sobreviventes e testemunhas do nazismo, percebemos que as narrativas, a partir dos discursos de seus descendentes, começam a privilegiar outros enfoques para assim falar da Shoá.

Tais percepçóes são apontadas por Frischer (2008), ao analisar as consequências do Holocausto em três geraçóes de judeus em três países distintos (Estados Unidos, França e Israel). Para a autora, a vivência do judaísmo apresenta algumas variaçôes entre os países analisados, havendo nos Estados Unidos o que ela chamou de "luto à distância", em outras palavras, as três gerações estadunidenses se engajaram mais ativamente na (re)construção da memória da tragédia, desdobrando-se em atitudes cujos traumas são transformados em açóes para impedir o esquecimento; nesse sentido, a cultura judaico-estadunidense promove uma progressiva universalização do Holocausto, que se torna uma alegoria a ser aplicada a outros eventos trágicos que solapam e agridem um determinado grupo social. ${ }^{1}$ Como apontado por Huyssen (2000: 12), está havendo uma "globalização do discurso do Holocausto".

Porém, ainda que com essas variaçóes nacionais, o que Frischer (2008) também observa é um "dever de memória" que perpassa as terceiras geraçôes

\footnotetext{
${ }^{1}$ O próprio autor da obra Tudo se ilumina, Jonathan Safran Foer, escreveu, em 2006, o livro Extremamente alto e incrivelmente perto (Extremely Loud and Incredibly Close), retratando as derivas de um garoto judeu nova-iorquino que perdeu o pai no atentado de 2001 ao World Trade Center. Nesta obra, percebemos como o discurso do Holocausto foi utilizado para elaborar o drama das Torres Gêmeas nova-iorquinas.
} 
dos países pesquisados. Estes netos de judeus da Segunda Guerra buscam respostas para os dramas que, antes de serem históricos, são para eles familiares; assim, enquanto os europeus, por viverem em proximidade com o espectro do nazismo e a ultradireita, tendem a uma atitude politizada, os estadunidenses direcionam o dever de memória para as produçóes culturais e a visita aos lugares arquivísticos do Holocausto dispersos pela Europa.

É neste contexto que lemos a obra Tudo se ilumina (2005), escrita por um autor norte-americano judeu, que tem como argumento uma viagem à Ucrânia em busca da vila (shtetl) onde teria nascido seu avô que fugiu dos nazistas em direção aos Estados Unidos. Em tal romance, podemos perceber como os arquivos familiares do personagem homônimo do autor, Jonathan Safran Foer, são revisitados e reorganizados ao longo da viagem que busca um retorno à terra de seus ascendentes judaicos.

A obra tem sua estrutura concebida a partir três grandes planos narrativos intercalados por capítulos: (i) o relato de viagem, escrito por Alexander Perchov (Sasha), o guia ucraniano de Jonathan-personagem, e que fala sobre a viagem que ambos empreenderam pela Ucrânia em busca de Augustine e do shetl de Trachimbrod; (ii) o romance histórico-maravilhoso escrito por Jonathan narrador-personagem após seu retorno aos EUA, reconstruindo o cotidiano do shtetl entre os anos de 1791 (data de sua fundação) e de 1942 (quando é invadido pelos nazistas); (iii) o romance epistolar, em que lemos as correspondências que Sasha envia a Jonathan, apresentando cartas cujas temáticas mesclam revisão dos manuscritos (ambos conversam sobre o processo de criação de suas obras) e confissões de uma amizade que se estrutura a partir do discurso fraterno e autobiográfico - ao menos pelo lado do ucraniano, pois é ele quem retruca as cartas que lhe foram enviadas por Jonathan, mas que por não terem sido publicadas no corpo do romance nos aparecem enquanto fantasmagorias às margens do texto impresso. No final, o que o leitor tem em máos é uma obra acabada e publicada, mas que no plano dos três enunciados se apresenta enquanto work in progress, por isso dizemos que o romance Tudo se ilumina se dobra sobre si, com três histórias intercaladas entre os capítulos e que se complementam na compreensão da obra.

Esteticamente, os três textos constituintes do romance sáo redigidos após o término da viagem empreendida pelos personagens, o que remete à nostalgia da experiência perdida e somente reconstruída em uma escrita alegórica, ou seja, a viagem se torna o espaço da melancolia, em uma coerência com o significado que esta adquire na literatura contemporânea, pois, como nos diz Paloma Vidal (2012: 90), "voltando à pergunta sobre o que se pode extrair hoje dos deslocamentos, diria que se volta da viagem com as máos vazias, o que não significa que com isso não se possa fazer alguma literatura”. 
Simbolicamente, Sasha recupera o tempo da viagem através da escrita do relato, enquanto Jonathan refaz no romance histórico-maravilhoso o espaço e a pessoa náo encontrados; assim, enquanto o primeiro aponta para o percurso, o outro remete aos encontros impossíveis desta jornada, à melancolia da terra judaica perdida. Todavia, como veremos, há uma intertextualidade entre estes dois planos pois, nos relatos, que se posicionam como tempo-verdade de uma vivência de viagem, temos os lastros do tempo-ficção que gerará o romance.

Por isso, consideramos o relato como a linha mestra da qual derivam as outras duas narrativas. A partir deste narrar a falta e o não-encontrado, bem como as descobertas e as melancolias do deslocamento, buscaremos perceber como se constroem as premissas que sustentarão a narrativa do romance histórico-maravilhoso, ou seja, pretendemos descobrir como a viagem realizada por Jonathan tem impacto em suas percepções sobre a vida e o arquivo histórico-familiar do Holocausto, bem como serve de recurso estilístico na escrita de seu romance cujo argumento se propóe a constituir para si uma genealogia judaica que lhe coloca como herdeiro de uma tradição.

\section{Viagens para resgatar os arquivos perdidos}

No romance Tudo se ilumina, como narra o próprio Sasha, Jonathan “está procurando a aldeia natal do avô dele, e alguém, que ele chama de Augustine, que salvou o avô dele na guerra. Deseja escrever um livro sobre a aldeia ${ }^{2}$ do avô" (FOER, 2005: 14). E é ainda Sasha quem explica a relação de sua família - ucraniana e cristã - com os judeus norte-americanos interessados neste resgate do passado:

Papai labuta numa agência de viagens denominada Herança Turismo. É uma agência para judeus, feito o herói, que têm ânsias em deixar a América, aquele país enobrecido, e visitar aldeias humildes na Polônia e na Ucrânia. A agência de papai conta com um tradutor, um guia e um motorista para esses judeus, que tentam descobrir os lugares onde suas famílias viviam outrora. Tá legal, eu jamais conhecera um judeu antes da viagem. Mas isso era culpa deles, e náo minha, pois eu sempre estivera disposto, e pode-se ressaltar, até que de uma forma desinteressada, a conhecer um deles. Vou ser verdadeiro novamente e mencionar que antes da viagem eu era de opiniáo que os judeus estavam tendo merda entre os miolos. Pois a única coisa que eu sabia dos judeus era que eles pagavam muita moeda-corrente a papai a fim de viajar de férias da América para

\footnotetext{
${ }^{2}$ Trachimbrod é o nome do shtetl literário, mas que remete ao vilarejo em que o avô do autor nasceu. Sem nos aprofundarmos no assunto, vemos que o próprio romance é uma alegoria dos arquivos familiares do escritor, que antes mesmo de escrever Tudo se ilumina também empreendeu uma viagem à Ucrânia em busca de seus antepassados judeus que migraram para os EUA fugindo do nazismo.
} 
a Ucrânia. Mas então conheci Jonathan Safran Foer, e posso dizer que ele não está tendo merda entre os miolos. Ele é um judeu criativo. ${ }^{3}$ (FOER, 2005: 9)

Tal citação traz diversas inquietaçóes que permearão a obra, sendo que a palavra herança é significativa de todo o texto: pois ao mesmo tempo em que Jonathan, nomeado como "herói ${ }^{4 "}$ por Sasha, está em busca da herança judaica de sua família, percebemos também que a agência em questão é um empreendimento hereditário da família Perchov, já que o Alex-avô lá iniciou sua carreira ainda na década de 1950, sendo, posteriormente, a vez de Alex-pai ingressar na mesma empresa, sugerindo que o cargo seria também transmitido para Alex-filho, que já trabalha como guia-intérprete. Na "Herança Turismo" ucraniana, temos três gerações, mas um único nome (Alex), reforçando que a questão geracional dos traumas judaicos também propiciou o surgimento de empreendimentos que vão passando de pai para filho e que lucram com esses sentimentos psicanalítica e historicamente ainda mal-resolvidos.

Porém, a viagem empreendida não se realiza em sua razão declarada, em sua proposta pré-definida e programada de reencontro com as memórias familiares, uma vez que o vilarejo já não mais existe, tendo sido totalmente devastado pela guerra, e o paradeiro da Augustine continua um mistério para todos - aliás, ela só existe em uma foto que Jonathan carrega consigo, e mesmo assim ele não aparenta ter plena certeza de que é esse o nome rabiscado pelo avô atrás de tal fotografia-arquivo.

Como já foi apontado por Derrida (2001), tradicionalmente, o ideário de arquivo está voltado para o passado, como se já estivesse pronto, fechado e lacrado; porém, o filósofo sugere um revisionismo, direcionando a percepção para o futuro, em uma eterna construção de significados: é um devir, em que o fechamento do conceito está sempre no além, no porvir. $\mathrm{O}$ arquivo seria uma promessa, seria messiânico (DERRIDA, 2001), o que coaduna com esta busca fracassada de Jonathan pelos seus registros familiares - afinal, tais

\footnotetext{
${ }^{3}$ Para o presente artigo, estamos usando a versão traduzida por Paulo Reis e Sérgio Moraes Rego. Vale mencionar que o personagem Sasha, autor deste plano narrativo, é um ucraniano com conhecimentos básicos de inglês, logo, sua escrita é truncada, algumas vezes com construçôes de frases que soam estranhas a um falante nativo da língua inglesa. A versão brasileira manteve no português esta escrita de estranhamento, de alguém que se expressa na língua do outro.

${ }^{4}$ Vale observar que esta nomeação apresenta um grau de ironia do autor (e não do personagem-narrador, pois este náo parece dar conta de tal sarcasmo e a emprega mesmo de maneira pueril): herói remeteria à jornada do herói campbelliano, mas a contrário dessa estrutura narrativa mítica, em Tudo se ilumina o personagem Jonathan, que sai em busca de uma pessoa e de uma local, nada encontra e volta de mãos vazias e mais atrapalhado em seus arquivos, ou seja, a viagem não serve para resolver e nem para apaziguar as relaçôes homem-mundo, como a jornada mítica tradicional se propóe. O herói dessa narrativa náo salva, nem reorganiza e muito menos estabelece a ordem perdida, pelo contrário, ele promove a subversão de toda uma situação familiar, que traz a luz pela sua viagem, mas que deixa em aberto para que cada um busque se virar com ela.
} 
arquivos fechados e capazes de proporcionar a satisfação de uma plenitude deverão sempre permanecer latentes enquanto objetos desejados, logo, se tornam um devir cujo encontro está sempre adiado. $\mathrm{O}$ encontro com o absoluto se torna uma impossibilidade.

Por outro lado, o que eles encontram é a casa de uma judia sobrevivente da passagem dos nazistas pela Ucrânia, chamada Lista, que em um primeiro momento creem ser a própria Augustine e assim passam a nomeá-la, dando-lhe um codinome que é nada mais do que a vontade de forçar o encontro com tais arquivos absolutos. Mas ela não é Augustine, é somente uma antiga moradora de Trachimbrod.

Vivendo sozinha em sua casa nas proximidades de onde localizava o antigo shtetl, Lista (espectro de Augustine) guarda consigo caixas e mais caixas com diversas lembranças dos antigos moradores de Trachimbrod. Nas palavras do narrador, Sasha:

Primeiro, preciso descrever que Augustine tinha um andar muito inusitado, que ia de cá pra lá pesadamente. Ela não conseguia se mover mais depressa do que devagar. Parecia ter uma perna prejudicada permanentemente. (Se já soubéssemos então, Jonathan, será que teríamos entrado?) Segundo, preciso descrever a casa dela. Náo era similar a qualquer casa que eu houvesse visto, e acho que eu não apelidaria aquilo de casa. Se você quer saber de que eu apelidaria aquilo, apelidaria de dois-quartos. Um dos quartos tinha uma cama, uma escrivaninha pequena, uma cômoda e muitas coisas do chão até o teto, incluindo pilhas de mais roupas e centenas de sapatos de diferentes tamanhos e estilos. Eu não conseguia ver as paredes por trás de todas as fotografias. Parecia que elas eram de muitas famílias diferentes, embora desse para reconhecer que algumas daquelas pessoas estavam em mais de uma ou duas. A roupa, os sapatos e as fotografias me fizeram raciocinar que deveria haver pelo menos cem pessoas morando naquele quarto. O outro quarto também era muito populoso. Havia muitas caixas, que transbordavam de artigos. Tinham coisas escritas nos lados. Um pano branco sobrepujava de uma caixa onde se lia CASAMENTOS E OUTRAS COMEMORAÇÓES. A caixa onde se lia PARTICULARES: REGISTROS/DIÁRIOS/ CADERNOS DE DESENHO/ROUPA DE BAIXO estava tão atulhada que parecia preparada para romper. Havia uma outra caixa onde se lia PRATARIA/PERFUME/CATA-VENTOS DE PAPEL, outra onde se lia RELÓGIOS/INVERNO, outra onde se lia HIGIENE/CARRETÉIS/VELAS, e outra onde se lia BONECOS/ÓCULOS. Se eu fosse uma pessoa inteligente, teria registrado todos os nomes num pedaço de papel, como o herói fez no seu diário, mas eu náo era uma pessoa inteligente e depois esqueci muitos deles. Alguns dos nomes eu náo consegui raciocinar, como a caixa onde se lia ESCURIDÃO, ou a que tinha MORTE DO PRIMOGÊNITO escrito a lápis na frente. Observei que havia uma caixa no alto de um desses arranha-céus de caixas onde se lia POEIRA. (FOER, 2005: 198)

Embora extensa, tal citação é sintomática da estrutura da casa da personagem e das percepçóes do visitante. Lista vive sozinha, mas está povoada 
pelos espectros dos moradores de Trachimbrod. Uma passagem anterior, quando Alex narra a sua aproximação da casa de Lista, é poética e também expressiva desta questão:

A casa era de madeira branca e estava desmoronando por si mesma. Havia quatro janelas, e uma delas estava quebrada. Andei mais aproximadamente, e percebi a mulher aboletada nos degraus. Era muito idosa, e descascava a pele de espigas de milho. Muitas roupas jaziam pelo quintal. Tenho certeza que estavam secando depois de uma lavada, mas estavam em arrumaçóes anormais, e pareciam as roupas de invisíveis corpos mortos. Raciocinei que havia muitas pessoas na casa branca, pois eram roupas de homens, roupas de mulheres, roupas de crianças e até de bebês [...]. Devia custar muito, pensei eu, cuidar de tantas pessoas como ela fazia. (FOER, 2005: 161-162)

Trachimbrod, destruída e dizimada pela guerra, está arquivada por Lista. Assim, ela se torna o "arconte do arquivo" (DERRIDA, 2001), aquela que o interpreta, o organiza e o protege. Essa percepção estaria inscrita no próprio nome da personagem: Lista, que pode ser tanto o substantivo feminino (“A” lista: uma relação, uma série de nomes de pessoas ou de coisas) quanto o verbo "listar" no imperativo (tu lista). A personagem guarda em sua casa, em sua vida e em seu nome, todo o conceito de arquivo, do Arkhê:

Arkhê, lembremos, designa ao mesmo tempo o começo e o comando. Este nome coordena aparentemente dois princípios em um: o princípio da natureza ou da história, ali onde as coisas começam - princípio físico, histórico ou ontológico -, mas também o princípio da lei ali onde os homens e os deuses comandam, ali onde se exerce a autoridade, a ordem social, nesse lugar a partir do qual a ordem é dada - princípio nomológico. (DERRIDA, 2001: 11)

Lista é um começo (enquanto substantivo feminino, em seu nome vemos repertoriado tudo que serve à rememorização do shtetl) e também um comando - embora fiquemos nas divagaçóes se "lista", enquanto imperativo que a nomeia, aponta para si mesma ou para seus interlocutores. Em direção aos outros, a personagem se torna agente ativa, toma o controle e obriga o outro a listar algo, a organizar um discurso; por outro lado, ao se sujeitar à ação, ela estaria em um estado de subordinação, sendo, neste sentido, obrigada - por quais forças? Por quais impulsos? - a arquivar Trachimbrod.

Consequentemente, se Lista pode ser interpretada enquanto o arconte do shtetl, sua casa se transforma em um "Arkheîon grego" (DERRIDA, 2001) - a casa do registro, da memória, o domicílio onde reside o arconte e seus arquivos. E ao empacotar em sua casa a territorialidade de Trachimbrod, ela domestica tal arquivo, passando-o do público ao privado.

Todavia, sua metodologia de classificação dos objetos para o arquivamento nos escapa (a nós, enquanto leitores e aos demais personagens que são 
no Arkhê̂on recebidos), já que suas caixas apresentam combinações e temas que saltam para uma realidade outra, fora das nossas percepçóes, sugerindo uma anarquia no arquivo. No entanto, esta sistematização que nos aparenta uma desorganização no plano racional pode também sugerir que os pressupostos de vivências da arconte, de Lista enquanto antiga moradora de Trachimbrod, ocorriam em um outro plano da experiência cotidiana, projetando o próprio shtetl já destruído para uma patamar de organização onírica e/ou maravilhosa, cujas ordens sociais, de classificaçáo e hierarquização seriam outras, e não as nossas (ocidentais, racionais, cristãs).

Lista é um arconte imerso na estética judaica, em que as etiquetas das caixas, enquanto textos, não são apresentadas de maneira cronológica e nem buscam dar conta de uma totalidade autoexplicativa. Suas caixas devem ter suas estruturas decifradas: FRONHAS, CANDELABROS/TINTA/CHAVES, CABELO/ESPELHO DE MÃO, POESIA/PREGOS/PEIXES, XADREZ/ RELÍQUIAS/MAGIA NEGRA, ESTRELAS/CAIXAS DE MÚSICA, SONO/ SONO/SONO, MEIAS COMPRIDAS/XÍCARAS DE KIDDUSH, ÁGUA EM SANGUE, RESTOS.

Todas escritos em caixa alta, as etiquetas enquanto categorias nos demonstram que, como já sugeriu Derrida (2001), a forma de arquivar também dita o conteúdo do arquivo. Diferente de uma estrutura greco-cristá, representada por "Homero, [onde] tudo ocorre à vista do leitor, em um presente temporal absoluto que é uniformemente iluminado" (HANDELMAN, 1982: 29), os rótulos que misturam aleatoriamente os objetos obedecem uma estética judaica, iluminando somente aquilo que interessa. Em paralelo com as discussóes de Handelman (1982: 31) sobre a estética da Bíblia, podemos mencionar que os arquivos de Lista apontam "não para fora em direção a imagens e formas, mas para dentro, em direção a si mesmo, à sua própria rede de relaçóes, de ambiguidades temporais e verbais".

Tais objetos, recolhidos e etiquetados nesta maneira polissêmica, foram escavados da terra, como disse Lista: "o chão ainda está cheio de anéis, dinheiro, fotografias e coisas judaicas. Eu só consegui achar algumas, mas elas enchem a terra" (FOER, 2005: 206). E neste ato de arqueologia, a Arconte ilumina o que restou daquela comunidade, organizando os traços daquilo que já foi e que agora só existe na memória de uso dos objetos resgatados. Por isso que Alex, ao encontrar Lista pela primeira vez e lhe informar que estavam a procura do vilarejo obtém como resposta: "Vocês chegaram. Eu sou Trachimbrod" (FOER, 2005: 164).

Ao encontrar Lista e sua casa, o arconte e o Arkheîon de Trachimbrod, os viajantes se aproximam o máximo que podem das memórias de Augustine e do shtetl. A partir daí, não há mais nada a ser encontrado, pois a casa de Lista 
é a própria territorialidade do vilarejo concentrada nestes objetos recolhidos logo após a invasão nazista. Porém, mesmo sendo informado que o encontro seria com o vazio e o nada, o personagem Jonathan insiste que Lista os leve até o local exato, o epicentro mítico onde o vilarejo de Trachimbrod se localizava.

$\mathrm{Na}$ narrativa de Alex:

- Ela diz que nós chegamos - disse eu ao herói.

$-\mathrm{O}$ quê?

- Eu informei a você que náo haveria nada - disse ela - Foi tudo destruído.

- Como assim, nós chegamos? - perguntou o herói.

- Diga a ele que isso é porque está muito escuro - disse-me o Vovô. - E que poderíamos ver mais coisas se não estivesse táo escuro.

- Está tão escuro - disse eu a ele.

- Não - disse ela. - Isso é tudo que vocês veriam. Está sempre assim, sempre escuro.

Imploro a mim mesmo para conseguir pintar Trachimbrod, para que você saiba por que estávamos tăo impressionados. Náo havia nada. Quando pronuncio "nada", náo quero dizer que náo havia nada exceto duas casas, um pouco de madeira no solo, pedaços de vidro, brinquedos de criança e fotografias. Quando pronuncio que não havia nada, o que tenciono dizer é que não havia nenhuma dessas coisas, nem outras coisas. (FOER, 2006: 247)

Nada foi encontrado no âmbito de um urbano demarcado: não há ruínas, não há lastros físicos de algo que representasse um tempo histórico, mas somente uma placa-monumento, que remete a uma homenagem ao shtetl, e assim se estrutura como uma memória pública e asséptica:

A pedra dizia em russo, ucraniano, hebraico, polonês, ídiche, inglês e alemão: ESTEMONUMENTO FOI ERGUIDOEM MEMÓRIADOS 1.204 HABITANTES DE TRACHIMBROD MORTOS PELAS MÃOS DO FASCISMO ALEMÃO EM 18 DE MARÇO DE 1942.

Inaugurado em 18 de março de 1992.

Yitzhak Shamir, Primeiro-Ministro do Estado de Israel.

(FOER, 2006: 257. Grifos do autor.)

Trachimbrod existe, por um lado, a partir deste monumento institucionalizado pelo Estado e, do outro, pelos objetos acumulados por Lista. Mas, se esta ausência do espaço físico é uma decepção, o excesso de coisas aleatoriamente acumuladas por Lista piscam a Jonathan como se fossem vaga-lumes reverberando uma luminescência do passado, servindo como gatilho para que ele escreva sua versão real-maravilhosa da história e da vida cotidiana em Trachimbrod. É esta experiência de desencontro, esta viagem que deu errada e desandou no plano pragmático, que fará com que ele recrie a gênese literária do shtelt, realizando a sua passagem do papel de viajante ao de escritor. 


\section{Revirando os arquivos para fazer renascer Trachimbrod}

Como dito anteriormente, os arquivos de Lista tornam-se textos sagrados a serem iluminados pela interpretação: sendo um acúmulo de rótulos e objetos polissêmicos, é impossível analisá-los linearmente. Por isso, consideramos que os arquivos de Lista são alegorias para o texto bíblico, contendo nas caixas os espólios do shtetl real e os embriôes da Trachimbrod literária. Tais caixas falam do Apocalipse do vilarejo concreto e contêm virtualmente a Gênese do vilarejo ficcional, que escapa para um urbanismo e para uma cotidianidade fantásticos, ou seja, uma realidade paralela, onírica e maravilhosa, assim como aquela que Jonathan tomou contato enquanto hóspede de Lista.

É desta maneira que ele narra, nos capítulos que remetem ao romance histórico-maravilhoso, o nascimento literário da vila de Trachimbrod:

Era 18 de março de 1791 quando a carroça de eixo duplo de Trachim B prendeu-o, ou não o prendeu no fundo do rio Brod. As jovens gêmeas W foram as primeiras a ver os objetos curiosos que subiam à superfície: cobras serpenteantes de barbante branco, uma luva de veludo com os dedos esticados, carretéis vazios, pincenê, amoras variadas, fezes, babados e rendinhas, os fragmentos de um pulverizador estilhaçado, e uma folha de resoluçôes escrita em tinta vermelha que sangrava: Vou... Vou...

Hannah começou a gritar. Chana ergueu acima dos joelhos os laçarotes de lá que amarravam as pontas dos seus culotes, e entrou na água fria. Foi recolhendo com os braços os detritos de vida que se erguiam à medida que avançava [...]. Estão aparecendo as coisas mais estranhas! Disse Chana rindo e espirrando água na crosta que crescia feito um jardim à sua volta. Pegou as mão de uma boneca-bebê, e os ponteiros de um relógio de parede antigo. Varetas de guarda-chuvas. Uma chave-mestra. Os artigos iam se elevando, coroados por bolhas que estouravam ao chegar à superfície. Um pouco mais jovem e menos cautelosa que a irmã gêmea, ela passava os dedos pela água e a cada vez apanhava uma coisa nova: um cata-vento amarelo, um espelho de mão lamacento, as pétalas de um miosótis afundado, areia, grãos de pimenta preta rachada, um pacote de sementes... (FOER, 2005: 16)

Os mesmos objetos, encontrados empacotados na casa de Lista, agora borbulham e emergem das águas, também de forma aleatória, dando origem ao mito fundador do shtetl. Se Lista os cavou da terra, Jonathan os faz borbulhar e vir à tona na água. Como a história do vilarejo foi recriada após o encontro do viajante-autor com Lista, este momento se torna o epicentro que desencadeia tais metáforas, pois, como sugere Derrida (2001: 11), o arquivo é "ali onde as coisas começam - princípio físico, histórico ou ontológico [...]". Esta transposição alegórica do vivenciado ao narrado é coerente, pois temos que nos recordar que Jonathan copiou, em seu diário, o nome de todas as etiquetas encontradas na casa da personagem; no mais, sua personalidade é de 
um colecionador, que embala tudo que encontra em sacos plásticos chamados Ziploc - atitude que justifica o seu interesse pelos objetos acumulados por Lista e que lhe marcam como referência em sua escrita.

Posterior a esta passagem, narrada no capítulo "O começo do mundo frequentemente chega”, descobrimos que há uma sobrevivente do naufrágio: "No meio dos barbantes e penas, cercada por velas e fósforos encharcados, camaróes, peóes de xadrez e borlas de seda que faziam reverência como águas-vivas, via-se uma menininha, um bebê ainda coberto de muco, rosado como a polpa de ameixa" (FOER, 2005: 22). Este bebê, posteriormente nomeado de Brod, como o rio, é colocado pelo narrador como sendo "a mãe da mãe da minha tataravô" (FOER, 2005: 26). E, neste gesto, Jonathan, personagem-escritor, insere-se de vez na genealogia do surgimento do vilarejo, tendo uma linhagem que o remete diretamente ao mito fundador - Brod, que, surgindo dos escombros do rio, veio à tona embalada pelos objetos acumulados por Lista. Por isso, podemos também ler sua obra enquanto um romance de filiação.

Já o carroceiro Trachim nunca mais foi encontrado, mas seu naufrágio e as apariçóes dos objetos acabaram por nomear o vilarejo: Trachim + Brod - a uniáo do nome do desaparecido com o rio onde tudo aconteceu. Desta forma, a cidade é fundada a partir do nome do viajante-comerciante, que por lá passava e que por lá pereceu.

Foi também este evento que deu origem ao Festival Dia-de-Trachim, que caracterizava a festa de fundação da aldeia:

Bitzl Bitzl R conseguiu recuperar a carroça alguns dias depois, com a ajuda de um grupo de homens fortes de Kolki, e suas armadilhas nunca haviam visto tanto movimento. Mas, ao vasculhar os despojos, eles não encontraram corpo algum. Durante os cento e cinquenta anos seguintes, organizou-se um concurso anual para "achar" Trachim, embora em 1793 uma proclamaçâo do shtetl tenha cancelado a recompensa - pois, segundo Menasha, qualquer corpo comum começaria a se desintegrar após dois anos na água, de onde que a busca não só tornara-se desprovida de sentido, como poderia resultar em achados bastante ofensivos, ou em recompensas múltiplas, coisa que seria até pior - e o concurso transformou-se numa série de festivais, para os quais uma linhagem de padeiros rabugentos criava folheados especiais, e as moças do shtelt se vestiam como as gêmeas naquele dia fatídico: culotes de lá amarradas com laçarotes, e blusas de lonita com golas-borboleta franjadas de azul. Homens percorriam grandes distâncias para mergulhar em busca dos sacos de algodâo que a Rainha do Desfile lançava no rio Brod, todos cheios de terra, menos um, o saco dourado. (FOER, 2005: 24)

Aqui, então, percebemos um terceiro patamar de alegoria: os objetos encaixotados e etiquetados por Lista são libertados e passam a borbulhar para flutuar nas águas do rio Brod pelas narrativas de Jonathan, que por sua vez são transmutados em sacos de algodão pelos moradores do shtelt. Temos, 
assim, três camadas de recuperação do arquivo urbano de Trachimbrod: os objetos acumulados por Lista pós-apocalipse se tornam mito fundador para a gênese literária do vilarejo que, finalmente, passam a ser ritualizados pelos moradores nos festejos comemorativas de aniversário do shtelt. Em outros termos: a casa de Lista é o referente que inspirou o romance de Jonathan e, na própria estrutura diegética de sua obra, também passou por mais uma cama de alegorização.

O processo da transmutaçáo da vivência ao texto traz, assim como no pisca-pisca dos vagalumes, a pulsáo de vida e de morte freudianos: os objetos, mortos e empacotados no plano real, ressurgem vivos no plano literário. Como nos diz Didi-Huberman (2011: 127):

O valor da experiência caiu de cotação, mas cabe somente a nós, em cada situação particular, erguer essa queda à dignidade, à 'nova beleza' de uma coreografia, de uma invenção de formas. Não assume a imagem, em sua própria fragilidade, em sua intermitência de vaga-lume, a mesma potência, cada vez que ela nos mostra sua capacidade de reaparecer, de sobreviver?

Destruído, o vilarejo ressurge na literalidade de seus escombros. Como um vaga-lume, o arquivo encaixotado pisca e renasce na organizaçáo narrativa de Jonathan, tornando-se o mito fundador de Trachimbrod. Por isso, compreendemos que o romance Tudo se ilumina é uma mise-en-abyme dos arquivos familiares de uma tradição judaica em diálogo com as vivências de uma viagem que buscava reencontrar tais referências geracionais. É também um ato de transformar uma experiência de viagem em uma linguagem literária, construindo uma alegoria através do vazio da anti-descoberta, ou melhor, através do que foi possível encontrar.

\section{Considerações finais}

O presente artigo teve como objetivo compreender como a viagem dos personagens de Tudo se ilumina não se realiza no plano do esperado, pois o encontro com os arquivos é um desejo, que como tal nunca se realiza satisfatoriamente. Logo, também podemos perceber o livro como uma crítica ao culto da memória material e demarcada territorialmente, bem como ao turismo de raiz, aquele que pretende apresentar as terras de seus antepassados às atuais geraçôes. As viagens são, assim, mais rizomáticas do que axial, como poderíamos derivar dos termos deleuzianos. Apreendemos que nenhum retorno é possível, que as memórias não estão lá, arquivadas para serem comercializadas. O que há é o vazio para a alegoria.

Mas, mesmo assim, as vivências da viagem possibilitam encontrar, se não o arquivo desejável, ao menos os seus lastros, seus resíduos, que se revolvem 
em elementos a serem iluminados ao se tornarem centelhas para o romance posteriormente escrito pelo viajante. Jonathan, assim, diferente de Alex, não deseja escrever o relato da sua viagem, mas deseja encontrar uma outra forma - no caso o romance - para narrar suas experiências de deslocamento. Por isso, mais do que falar de si, ele transforma suas vivências em uma cosmogonia para Trachimbrod.

O livro fala de transformaçóes dos arquivos históricos familiares ou, melhor, trata-se de um "anarquivamento do arquivo" nos moldes derridianos da desconstrução. Pudemos, então, demonstrar como a Trachimbrod literária de Jonathan começa ali, quando transforma os objetos acumulados e encaixotados de Lista em gênese do seu vilarejo erguido com doses generosas de realismo mágico.

Se os judeus são considerados os povos dispersos, estes objetos memorialísticos encaixotados por Lista renascem como vagalumes que sobreviveram à morte e ao apocalipse. Tais objetos/seres que apagam e acendem são metáforas para os "povos expostos ao desaparecimento" (DIDI-HUBERMAN, 2011: 96).

Como diz o poema de Ungaretti, escrito nas trincheiras da Primeira Guerra Mundial, em 1917, "Ilumino-me, de imenso". O poeta quis demonstrar, de forma concisa, como a manhã das trincheiras (por isto o título Mattina) sempre trazia esperanças de um novo dia, e assim ele se descobria vivo e pertencente à Natureza. Mostra a nossa (in)significância perante o Universo, mas também demonstra que somos todos um, que não há solidão porque fazemos parte de uma Humanidade.

Tudo se ilumina apresenta a cadência de acende-apaga dos vagalumes, pois nos traz estas percepçóes de que as viagens empreendidas em busca de arquivos familiares nos leva quase sempre a um encontro com vazios, lastros e sobras, mas que merecem ser iluminados a partir das histórias que nos contamos para não esquecermos de onde viemos e quem somos.

\section{Referências bibliográficas}

DERRIDA, Jacques. Mal de arquivo: uma impressão freudiana. Rio de Janeiro: Relume Dumará, 2001.

DIDI-HUBERMAN, Georges. Sobrevivência dos vaga-lumes. Belo Horizonte: Ed. UFMG, 2011.

FOER, Jonathan Safran. Tudo se ilumina. Rio de Janeiro: Ed. Rocco, 2005.

FRISCHER, Dominique. Les enfants du silence et de la reconstruction: la Shoah en partage - trois générations, trois pays: France, États-Unis, Israël. Paris: Bernard Grasset, 2008.

HANDELMAN, Susan A. The slayers of Moses: the emergence of rabbinic interpretation in modern literary theory. Albany: State University of New York Press, 1982. 
HUYSSEN, Andreas. Seduzidos pela memória: arquitetura, monumentos, mídia. Rio de Janeiro: Ed. Aeroplano, 2000.

VIDAL, Paloma. "Viagem e experiência comum: o filho da mãe, de Bernardo Carvalho”. In: DALCASTAGNÈ, R. \& MATA, L. N. da. (Org.). Fora do retrato: estudos de literatura brasileira contemporânea. Vinhedo, SP: Ed. Horizonte, 2012.

Humberto Fois-Braga é Professor no Departamento de Turismo da Universidade Federal de Juiz de Fora - UFJF e doutorando em Letras: Estudos Literários pela mesma instituiçáo. Pesquisa nos seguintes temas: mobilidades contemporâneas, literatura brasileira contemporânea, coleçóes literárias, narrativas de viagem, produção de discursos audiovisuais, imaginários urbanos, hospitalidade e alteridade, tradução intersemiótica e curadoria.

E-mail: humfois@gmail.com

Recebido em: 13/05/2016

Aprovado em: 22/05/2016 